\title{
A NOMOGRAPH FOR DETERMINING HEAT STORAGE IN SEA ICE*
}

\author{
By N. UNTERSTEINER
}

THE specific heat of ice is a function of its temperature and salinity, due to the associated variation of equilibrium brine concentration. A detailed analysis of the problem has recently been given by Schwerdtfeger (1963). In practical applications it is sometimes laborious to calculate the amount of heat required for a given change of temperature of sea ice. To facilitate this task, a nomograph has been constructed (Fig. I). It is based on the approximate expression

$$
Q=0 \cdot 9\left(T_{2}-T_{1}\right)\left(0 \cdot 5+\frac{4 \cdot 1 S}{T_{1} T_{2}}\right)
$$

in which $Q$ denotes the amount of heat in cal. $\mathrm{cm}^{-3}, T_{1}$ and $T_{2}$ the initial and final temperature in ${ }^{\circ} \mathrm{C}$., and $S$ the salinity of the ice in $\mathrm{g}$. $\mathrm{kg} .^{-\mathrm{r}}$. The variation of density is neglected. This expression holds with an accuracy sufficient for most heat calculations in the range of temperature and salinity most commonly found in the polar regions. The way to use the nomograph is indicated by arrows, beginning at the left, for the example: $T_{\mathrm{I}}=-6 \cdot \mathrm{o}^{\circ} \mathrm{C}$, $T_{2}=-0.7^{\circ} \mathrm{C} ., S=2 \cdot 0 \%, Q=12 \mathrm{cal} . \mathrm{cm} .{ }^{-3}$.

MS. received 23 March 1964

\section{REFERENCE}

Schwerdtfeger, P. ${ }_{1963}$. The thermal properties of sea ice. Fournal of Glaciology, Vol. 4 , No. 36 , p. $789-807$.

* Contribution No. 84, Department of Atmospheric Sciences, University of Washington, Seattle, Washington, U.S.A. 


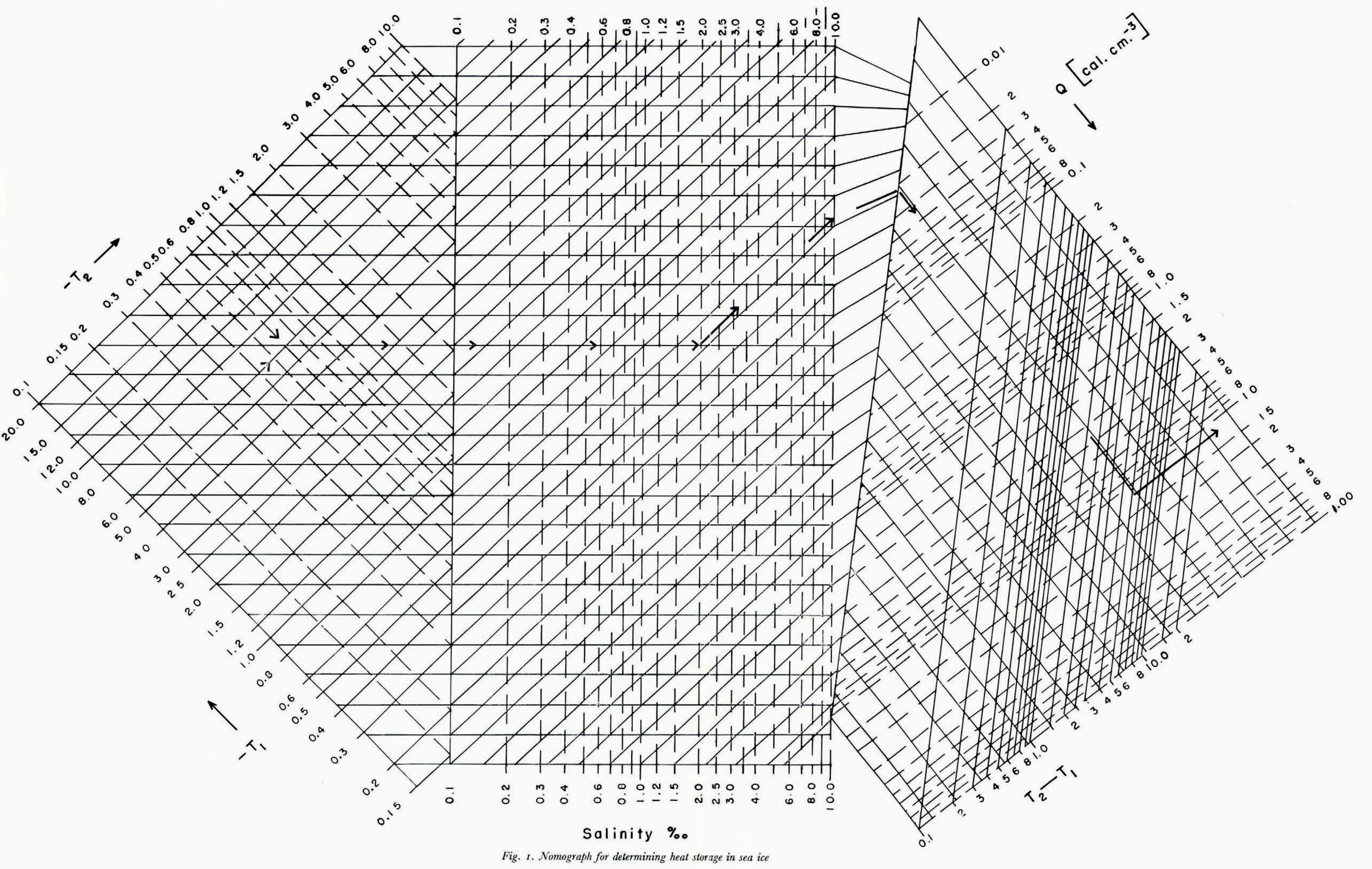

